\title{
A FUNÇÃO DA EXPERIMENTAÇÃO NA PERCEPÇÃO DE PROFESSORES DE CIÊNCIAS E MATEMÁTICA
}

\author{
Lorita Aparecida Veloso Galle \\ Geisa da Silva Medeiros ${ }^{2}$ \\ Cristiano Centeno Specht ${ }^{3}$
}

\begin{abstract}
Resumo: A questão central desta pesquisa é: qual a função da experimentação no ensino de Ciências e Matemática na percep̧çáo de professores dessas áreas? Depoimentos de 16 professores de Ciências da Natureza e Matemática foram analisados por meio da Análise Textual Discursiva. Após a análise, emergiram duas categorias: Experimentação com a função de facilitadora da aprendizagem e Experimentação com a funçấo viabilizadora da pesquisa em sala de aula. Os sujeitos apontaram a relevância da experimentaçấo como complementação da aula expositiva, de forma que uma náo substitua a outra e ambas sejam complementares. Compreende-se que o presente estudo possibilita a reflexão por parte dos docentes sobre atividades relativas à experimentação e à sua contribuição no âmbito da sala de aula.
\end{abstract}

Palavras-chave: Educação Básica; Experimentação no Ensino de Ciências e Matemática; Percepção de professores.

\section{THE FUNCTION OF EXPERIMENTATION ACCORDING TO THE PERCEPTION OF SCIENCE AND MATHEMATICS TEACHERS}

Abstract: The main question of this research is the following: which is the function of experimentation in teaching according to Science and Mathematics teachers? Testimonies by sixteen Nature Sciences and

1 Doutoranda em Educação em Ciências e Matemática da Escola de Ciências da Pontifícia Universidade Católica do Rio grande do Sul - PUCRS, Porto Alegre, Rio Grande do Sul, Brasil. E-mail: loritaveloso@hotmail.com

2 Doutoranda em Educação em Ciências e Matemática da Escola de Ciências da PUCRS, Porto Alegre, Rio Grande do Sul, Brasil. Docente da Universidade de Caxias do Sul - UCS. E-mail: gsmedeiros1@ucs.br

3 Mestre em Educação em Ciências e Matemática da Escola de Ciências da PUCRS, Porto Alegre, Rio Grande do Sul, Brasil. Docente do Instituto Federal Sul-rio-grandense - IFSUL- Camaquá. E-mail: ccspecht@hotmail.com 
Mathematics teachers were analyzed by means of the Discourse Analysis. Two categories emerged from the analysis: Experimentation as a learning facilitator and Experimentation as a research enabler in the classroom. The subjects pointed out the importance of experimentation as a complement to expository teaching, so that one does not replace the other, but rather they are complementary to each other. The present study may enable teachers to reflect on experimentation-related activities and the contribution this can provide in the classroom.

Keywords: Basic Education; Experimentation in Sciences and Mathematics teaching Teacher perception.

\section{Introdução}

Historicamente, atividades de experimentação existem há mais de 100 anos, com a socialização de atividades realizadas em sala de aula nas universidades, tendo como intento alavancar a aprendizagem de conceitos científicos (GALIAZZI et al., 2001). No século XX, com o advento do Sputinik ${ }^{4}$ na Rússia, houve uma mobilização dos Estados Unidos para organizar projetos visando à formação de cientistas. Disso derivou o investimento em atividades escolares que primassem pelo desenvolvimento de certas capacidades, como observação, registro e manejo de aparelhos de laboratório, entre outras (FAGUNDES, 2007). Nessa época, ocorreu universalmente uma propagaçáo de açóes com igual objetivo. O Brasil também participou desse movimento, e a visão de "formação de cientistas", herança desse momento histórico, ainda é persistente na Educação em Ciências, ou seja, a observação e a comprovação de fenômenos recebem atualmente destaque nesse campo do conhecimento.

Embora apontada como um destacado recurso para a aprendizagem, a experimentação no ensino de Ciências tem sido suprimida em prol de aulas com ênfase em conteúdos conceituais, que necessitam ser copiados e repetidos pelos próprios estudantes. Isso compromete a construção de redes de significados, conduzindo à ideia de que o conhecimento científico é algo pronto (FAGUNDES, 2007; CACHAPUZ et al., 2011). Entre os motivos assinalados pelos professores para esse tipo de abordagem (FAGUNDES, 2007), estão, por exemplo, a falta de material, o espaço físico, a própria formação docente e a organização curricular.

Alguns estudos discutem a experimentação no espaço escolar, podendo-se destacar: Moraes (1998), que promoveu um debate sobre as diversas concepçóes da experimentação no ensino de Ciências; Giordan (1999), que discutiu aspectos relativos ao papel da experimentação no ensino de Ciências; Izquierdo, Sanmartí e Espinet (1999), que apontaram as diferentes abordagens da experimentação em sala de aula e sua eficácia na aprendizagem, defendendo que essas atividades apresentam características singulares, diferentemente das atividades desenvolvidas por um cientista; e Galiazzi et al. (2001), que tentaram compreender os objetivos da experimentação no Ensino Médio por parte de professores e estudantes de Química.

4 Primeiro satélite lançado no espaço, em 1957, pela Rússia (ALTOÉ; SILVA, 2005). 
Atividades práticas têm potencialidades no ensino e na aprendizagem, mas, por si sós, não garantem que esses processos ocorram. A sua relevância está notoriamente nas açóes desenvolvidas durante sua execução, em detrimento do produto oferecido por esse tipo de abordagem (POZO, 2002). Portanto, a experimentação, como atividade prática, não pode ser compreendida como um fim em si mesmo (IZQUIERDO; SANMARTÍ; ESPINET, 1999; FAGUNDES 2007), mas como um espaço de debates e discussóes, tendo o professor como orientador do processo.

Os pressupostos epistemológicos que alicerçam a prática pedagógica do professor devem ser claros, ou seja, ele precisa ter em mente que tipo de capacidades pretende potencializar e desenvolver no decorrer da experimentação. Nesse sentido, um planejamento pode voltar-se para a simples validação do que já está "pronto" ou para o desenvolvimento de capacidades que valorizem procedimentos e atitudes, fomentando a autonomia pessoal e intelectual dos estudantes (LIMA, 2012).

Diante do exposto, este estudo tem como objetivo compreender como professores da Educação Básica percebem a função da experimentação no ensino e na aprendizagem de Ciências e Matemática. Para atingir o objetivo da proposta de investigaçáo, foram coletados depoimentos por escrito de 16 professores de Ciências e Matemática ingressantes de um curso de Mestrado em Educação em Ciências e Matemática.

Acredita-se que a relevância deste estudo se encontra no fato de que a experimentação, por vezes, é compreendida pelos educadores apenas como mais um recurso pedagógico disponível, sem que ocorra a reflexão dos pressupostos norteadores e da sua funçáo no aprendizado. Tal entendimento pode contribuir para que esse tipo de atividade seja pouco explorado e compreendido pelos professores, que por vezes o utilizam em situaçóes isoladas, como um recurso meramente ilustrativo. Por meio de uma análise mais consistente, é possível identificar outras funçôes consideráveis da experimentação, de modo que o professor possa explorar esse recurso de maneira mais efetiva, especialmente no ensino de Ciências e Matemática.

$\mathrm{Na}$ sequência do presente artigo, apresentam-se os pressupostos teóricos da investigação, os procedimentos metodológicos, a análise e discussão dos resultados, as consideraçôes finais e as referências utilizadas.

\section{Referencial teórico}

As atividades práticas no contexto escolar representam, para Hodson (1994), qualquer ação que permita colocar os estudantes em posição ativa. Constituem exemplos de atividades práticas, entre outros: trabalhos em grupo; coleta, análise e interpretação de dados; elaboração de gráficos; busca bibliográfica em livros ou na internet; construção de modelos; e entrevistas. No que se refere ao ensino de Ciências e Matemática, a experimentação representa uma atividade de caráter prático que 
pode auxiliar o estudante a realizar conexóes com os conceitos científicos, com sua consequente apropriação (ROSITO, 2003).

Os documentos oficiais têm legitimado as atividades práticas como um meio que auxilia o alcance dos objetivos propostos para a educação brasileira. Tal ideia encontra-se presente nos Parâmetros Curriculares Nacionais (PCN) da área de Ciências da Natureza e Matemática e suas Tecnologias (BRASIL, 2000). Nesse documento, são consideradas fundamentais as atividades que visem à investigação, à comunicação e ao debate de fatos e ideias por meio de observação, experimentaçáo, comparaçáo e estabelecimento de relaçóes entre fatos e fenômenos. O documento aponta a observação e a experimentação como estratégias didáticas que promovem a obtenção de informaçóes de fontes variadas, possibilitando a contextualização da problematização.

As Diretrizes Curriculares Nacionais da Educação Básica (DCNEB) (BRASIL, 2013) também referenciam a vivência prática dos estudantes, o que viabiliza compreender os fenômenos segundo diferentes perspectivas e pensamentos, em constante mudança no tempo, no espaço e na intencionalidade. A Base Nacional Comum Curricular (BNCC) (BRASIL, 2018, p. 321), ao elencar as competências da área de Ciências da Natureza, aponta a necessidade de imersão gradual dos estudantes em "[...] processos, práticas e procedimentos da investigação científica”, compreendendo-se que a experimentação tem aí um papel primordial.

É possível identificar o destaque dado a atividades que deslocam os estudantes de uma posição passiva (DEMO, 2007; LIMA, 2012), promovem sua participação e mobilizam capacidades imperativas para o aprimoramento de visóes de mundo e interaçóes com propriedade. Nesse sentido, a experimentaçáo no ensino e na aprendizagem vem também recebendo destaque (HODSON, 1994; GALIAZZI et al., 2001; ROSITO, 2003; OLIVEIRA, 2010, SANTOS; SOUZA, 2016), especialmente como uma ferramenta singular, capaz de implementar as açôes no âmbito da sala de aula, permitindo a reconstrução do conhecimento de modo dinâmico. Para Moraes (1998), as propostas alternativas para o ensino de Ciências devem primar pelo incremento de capacidades científicas e valorizar a organização das Ciências, seus preceitos e pressupostos em relaçáo ao currículo desse campo do conhecimento. $\mathrm{O}$ autor ressalta que essas propostas devem conduzir o estudante à emancipação pessoal e intelectual, promover a contextualização com demandas sociais, estabelecendo uma relaçáo estreita entre Ciência, tecnologia e sociedade, e ainda incentivar o diálogo entre as diversas áreas do saber.

Para Oliveira (2010), a experimentação no ensino de Ciências pode contribuir para o aprendizado nessa área do conhecimento no que diz respeito a conceitos, sua natureza e processos investigativos, bem como no que tange à relação com questóes tecnológicas e sociais. Segundo a autora, também pode colaborar para o desenvolvimento de atitudes, como o aprimoramento da atenção, atividades em equipe, tomada de decisóes, estímulo à criatividade, aprimoramento de procedimentos - como observação, registro, análise e proposição de hipóteses - e capacidade de operar com instrumentos. A autora reforça que as atividades 
experimentais possibilitam que o professor identifique fragilidades dos estudantes na apreensão de conceitos e faça os ajustes necessários para saná-las.

O planejamento e desenvolvimento de uma atividade de experimentaçáo podem revelar diferentes pontos de vista do professor sobre esse tipo de ação. $\mathrm{O}$ conhecimento das distintas concepçóes que guiam as atividades de experimentação, portanto, pode contribuir para sua organização e desenvolvimento. Moraes (1998) salienta quatro concepçóes que podem dirigir uma atividade de experimentaçáo:

- demonstrativa: as atividades têm como pressuposto a ideia de que a ciência representa uma verdade inquestionável. As açóes impedem a compreensão e a construçáo do próprio conhecimento, pois apenas realizam a demonstração de algo que já se encontra "pronto";

- empirista-indutiva: a observação representa o princípio e o papel do conhecimento; sendo assim, o conhecimento deriva daquilo que se pode observar;

- dedutivista-racionalista: a experimentação é guiada por suposições que derivam de hipóteses, as quais serão submetidas a uma testagem, tendo como base alguma teoria;

- construtivista: os conhecimentos construídos anteriormente são considerados, e a experimentação é configurada por meio de problemas que procedem do próprio contexto do estudante. É possível que assuma, por vezes, um viés interdisciplinar.

Assumindo-se que aprender é complexificar aquilo que já se conhece (MORAES, 2010), os experimentos demonstrativos, comprovativos e dedutivos têm eficácia reduzida para efetivar o aprendizado, uma vez que os estudantes ocupam um papel passivo, sendo apenas receptores de algo que já foi pensado/estruturado por outros. Assim, o espaço para relatos, discussôes e reflexôes é praticamente nulo.

$\mathrm{Na}$ concepção construtivista, o conhecimento é construído a partir do que já se conhece, com espaço para curiosidade e dúvida (SOLÉ; COLL, 2009). Adotar esta concepção implica primar por atividades de experimentação que valorizem os estudantes como sujeitos de sua própria aprendizagem, oferecendo-lhes espaço para seu protagonismo. Logo, isto implica que as açóes desenvolvidas não representam "algo pronto" para simples efetivaçáo, mas parte de problemas sugeridos pelos próprios estudantes, que, juntamente com o professor, determinam quais caminhos seguir para resolver os questionamentos. Tal posicionamento sugere considerar a pesquisa como princípio educativo (MORAES, 1998) e balizador das atividades.

A experimentação conduz ao que Demo (2007) compreende como questionamento reconstrutivo, pois, por meio de observaçáo, interpretaçáo e formulação, os estudantes ampliam sua capacidade de aprender a apreender e elaboram uma nova releitura do que já conhecem. A experimentação é capaz de gerar uma série de possibilidades, no sentido de que os estudantes se tornem autores de seu próprio conhecimento. Capacidades como a reelaboração de argumentos, o refazer com linguagem própria, a interpretaçáo com autonomia, o reescrever 
criticamente e a elaboração de textos próprios, entre outras, possibilitam que se supere a educação pela imitação, em que os estudantes são impelidos a reproduzir o conhecimento. É dessa forma que a experimentação pode auxiliar os estudantes a lerem a realidade com competência e a nela atuarem de maneira positiva e coerente com as necessidades da educação contemporânea.

\section{Metodologia}

A presente pesquisa tem abordagem metodológica qualitativa. Conforme Bogdan e Biklen (2010, p. 47-51), esse tipo de abordagem apresenta algumas características inerentes:

$\mathrm{Na}$ investigação qualitativa a fonte direta de dados é o ambiente natural, constituindo o investigador o instrumento principal. [...] A investigação qualitativa é descritiva. [...] Os investigadores interessam-se mais pelo processo do que simplesmente pelos resultados ou produtos. [...] Os investigadores tendem a analisar os seus dados de forma indutiva. [...] O significado é de importância vital na abordagem qualitativa.

Participaram do estudo 16 professores com graduação nas áreas de Biologia, Química, Física, Matemática e Pedagogia, ingressantes em um curso de mestrado em Educaçáo em Ciências e Matemática de uma instituição privada de Ensino Superior. A idade dos participantes varia de 22 a 55 anos, sendo a média de 35 anos. Em relação à experiência docente dos participantes, seja pública ou particular, sete professores têm menos de cinco anos de atuação, quatro têm entre cinco e dez anos, e cinco têm mais de dez anos de experiência. Cabe ressaltar que, no momento da coleta de dados, um dos professores não estava atuando em sala de aula.

Os dados coletados constituem as respostas, por escrito, formuladas pelos participantes à seguinte pergunta: qual a função da experimentação no ensino de Ciências e Matemática? As respostas foram analisadas com base nos procedimentos da Análise Textual Discursiva (ATD) (MORAES; GALIAZZI, 2013). Este método de análise apresenta as seguintes etapas: unitarização, que corresponde à desmontagem dos textos em unidades de significado com referência ao fenômeno estudado; categorização, etapa que se constitui no estabelecimento de relação entre as unidades, construindo-se categorias primárias, reagrupadas em categorias intermediárias, até constituírem as categorias finais da análise, que podem ser organizadas de modo emergente ${ }^{5}$ ou a priori; e construção de metatextos, estágio em que são elaborados textos analíticos, os metatextos, que expressam a compreensão renovada do corpus de análise.

Nesta investigação, emergiram duas categorias que manifestam as concepções dos participantes sobre a função da experimentação no ensino de Ciências e Matemática. As categorias emergentes são apresentadas a seguir por meio dos metatextos.

5 Neste estudo, utilizaram-se categorias emergentes. 


\section{Resultados e discussáo}

$\mathrm{Da}$ análise dos depoimentos dos participantes, emergiram duas categorias em relação às funçóes da experimentação no ensino e na aprendizagem em Ciências e Matemática: Experimentação com a função facilitadora da aprendizagem e Experimentação com a função viabilizadora da pesquisa em sala de aula. As categorias estão descritas mediante metatextos, com vistas a apresentar resposta à pergunta da investigação.

\section{a) Experimentação com a funçâo facilitadora da aprendizagem}

A partir dos depoimentos que emergiram nesta categoria, é possível compreender que uma das funções da experimentaçáo apontadas pelos professores é atuar como facilitadora da aprendizagem dos estudantes, na medida em que possibilita estabelecer uma relação entre a teoria e a prática, conferindo significado ao que se aprende e colaborando para a motivaçáo pessoal.

A experimentaçáo pode facilitar a aprendizagem, sendo capaz de aproximar a teoria da prática, além de desenvolver outras capacidades, conforme é mencionado por $\mathrm{P}^{6} 13$ : "A experimentação auxilia na compreensão de conceitos científicos, instiga o pensamento e a formulaçáo de ideias". Uma aula meramente expositiva oferece os conteúdos "prontos", muitas vezes considerados complexos, o que pode representar um obstáculo para o avanço do aprendizado. Logo, as práticas de experimentaçáo podem conduzir à compreensão dos conceitos com maior clareza. Em outro exemplo, P1 manifesta que a experimentação possibilita visualizar e entender conceitos complexos de uma maneira simples: "[...] a experimentação permite a materialização de algo que muitas vezes é totalmente abstrato".

O professor P14 compreende que a experimentação pode ocupar momentos distintos no planejamento e colaborar para os processos de abstração de conceitos que tenham ou venham a ser estudados teoricamente, dando-lhes concretude. O professor P14 explica: "Os experimentos, quando aplicados juntos ou ao final dos conteúdos, podem auxiliar na compreensão de alguns conceitos mais abstratos da ciência, visto que esses passam de um nivel abstrato para um nivel concreto: a própria experimentação".

Quando novos conceitos são agregados aos conhecimentos iniciais, pode iniciar-se um processo de valorizaçáo do próprio conhecimento por parte dos estudantes. A experimentaçáo favorece esse processo ao possibilitar que os estudantes estabeleçam relaçóes com o universo que os cerca, de forma palpável, conforme P2 observa: "O trabalho, quando exposto de forma concreta, traz mais significado para a aprendizagem". Isso também é reforçado por P14, que aponta a importância da relação entre os conhecimentos iniciais e os novos conhecimentos: "A experimentação serve de auxílio na compreensão de conceitos e no relacionamento destes com a realidade e suas aplicaçôes".

6 Para este estudo, os participantes foram identificados pela letra P, seguida dos números 1 a 16, de modo a manter o anonimato de seus depoimentos. 
$\mathrm{Na}$ visão dos educadores participantes, as aulas expositivas náo precisam ser banidas em favor de metodologias diferenciadas que primam pela reconstrução do conhecimento, como afirma P13: "A constância destas atividades práticas são uma complementação das aulas teóricas, e uma não substitui a outra”. Já o professor P8 afirma que "[a experimentação] pode ser um meio, uma estratégia para aquilo que se deseja aprender ou formar, e não o fim". Almeida (2012, p. 200) menciona a relevância de se estabelecer uma conexão coerente entre a teoria e a experimentação, objetivando-se conferir significados ao que se aprende e deixando-se de "[...] persistir na abordagem das técnicas de ensino de forma mecânica, não contextualizada, supervalorizando a memória do aluno em detrimento de sua habilidade de reflexão e crítica argumentada".

Por propiciar que os estudantes estabeleçam relaçôes entre os aspectos teóricos e práticos, os professores acreditam que a experimentação pode ser um modo de implementar as açôes de ensino e aprendizagem no âmbito da sala de aula. P1 reforça a potencialidade da experimentaçáo como "[...] uma estratégia didática que permite qualificar o processo de ensino e aprendizagem".

Para Freire (1993), o conhecimento constrói-se a partir da interação do educando com o meio, portanto, compreende-se que os conhecimentos trabalhados no âmbito da sala de aula devem fazer sentido para os estudantes, a ponto de estimular seu envolvimento. $\mathrm{O}$ papel do educador é criar situaçóes e propor atividades que levem à ação e à reflexão, sempre que possível partindo de atividades concretas. Tais situaçôes devem possibilitar o envolvimento de modo ativo, superando a mera comprovação, conforme aponta $\mathrm{P} 4$ : "A experimentação não é somente demonstração, mas um meio para o desenvolvimento do conhecimento".

Sobre o papel do professor, enfatiza-se a relevância de sua ação ao conduzir e realizar discussões que enriqueçam as atividades, propiciando espaço para novos aprendizados e tornando o ato de aprender significativo (FAGUNDES 2007). Para Demo (2007, p. 7), "a aula que apenas repassa conhecimento, ou a escola que somente se define como socializadora de conhecimento, náo sai do ponto de partida, e na prática, atrapalha o aluno, porque o deixa como objeto de ensino e instrução. Vira treinamento". O professor P13 evidencia que "o professor é o mediador, tem papel importante tanto na aula expositiva dialogada quanto na participativa".

A partir da conexão entre teoria e prática viabilizada pela experimentação, é possível que os estudantes venham a atribuir significação a conceitos ora teóricos e abstratos. Acredita-se que, no entendimento dos professores, a aprendizagem de conceitos isolados dificulta a apropriação de sentido e relação prática. A significação possibilita que os aprendizados efetivados pela experimentação sejam consolidados, conforme aponta P16: "Muitos depoimentos dos educandos são daquela aula em que se realizou uma destilação, não lembrando as demais aulas teóricas, demonstrando quanto é significativa e importante a experimentação no estudo de Ciências e Matemática".

A partir do momento em que os estudantes são conduzidos a participar de forma ativa em sua aprendizagem, eles passam a ser os protagonistas desse processo (DEMO, 2007; LIMA, 2012) e desenvolvem suas capacidades de modo amplo, 
como indica P16, compreendendo que a experimentação é um recurso que viabiliza o protagonismo:

O educando que manuseia, observa, socializa com o grupo e interage com o material em estudo é um educando que, ocupado em sua tarefa, aprende melhor por interação com vários sentidos, apresentando várias conexões com o objeto de ensino, pois se torna protagonista de sua prática e participante transformador da realidade.

Por meio da experimentação, os educandos podem perceber as aplicabilidades dos conhecimentos sistematizados em sua vida prática ao visualizá-los como parte de seu contexto. Portanto, há uma aproximaçáo entre o entendimento que propicia significado e o que se está aprendendo. $\mathrm{O}$ estudante pode compreender que aquele conhecimento é capaz de responder indagaçóes que porventura tenham surgido no andamento de uma aula expositiva ou até mesmo em alguma leitura sobre o assunto, por exemplo.

O professor P8 afirmou: "Através da experimentação, é possivel que se traga um significado às teorias que foram estudadas, tornando-as claras, não para serem comprovadas, mas para serem estudadas, compreendidas, discutidas ou até mesmo modificadas". A experimentaçáo em sala de aula pode, dessa forma, constituirse como instrumento para ilustrar o conteúdo proposto, instigar os estudantes a relacioná-lo com a prática e auxiliar na formulação de novas ideias e na compreensão de conceitos. Os estudantes, consequentemente, atribuem valor ao que estáo aprendendo.

A experimentação pode ser facilitadora da aprendizagem na ótica do professor P8, uma vez que se estabelece como aliada no encantamento dos estudantes, com vistas ao aprendizado de conhecimentos científicos. $\mathrm{Na}$ experimentação, as teorias passam a ter sentido para os estudantes. Mais ainda, ela facilita a criação de estímulos para despertar interesse e motivação para a aprendizagem, como explica P5: " $A$ experimentação serve também para despertar o interesse do aluno pelas aulas, pois, quando ele conclui algo em cima de um experimento, ele acaba se motivando a testá-lo e comprová-lo." Esta ideia é também apresentada por P6, que afirma: "Eles [estudantes] se divertem, se surpreendem e, dependendo de seu nivel de interesse, compreendem com maior facilidade os conceitos".

A motivação está relacionada com a capacidade de conseguir gerar no indivíduo estímulos concretos que o desafiem a procurar soluçóes. Muitas vezes, está relacionada com um processo de autorrealização do estudante por completar uma tarefa ou, de modo consciente/inconsciente, por transpor barreiras e desafiar seus limites (AZEVEDO; FARIA, 2006).

No que diz respeito às aulas de Ciências, os estudantes podem ter certas expectativas. Diz o professor P14: "Quando falamos em Ciências, logo os alunos se remetem à imagem de um pesquisador em um laboratório, com muitos frascos e explosões. Assim, quando trabalhamos a disciplina de Ciências, logo somos cobrados pela experimentação". Apresentar situaçôes que envolvam experimentação pode, de certo modo, concretizar as expectativas dos estudantes, estimulando seu 
interesse em aprender. Isso porque o ato experimental permite a criação de situaçóes desafiadoras para resolver questões teóricas de uma forma atrativa e assim mobilizar a aprendizagem.

Para Giordan (1999), a experimentação tem a capacidade de despertar o interesse dos estudantes, independentemente do nível de escolarizaçáo, pois sua organização metodológica proporciona uma forma diferenciada de aprender, com maior ludicidade; logo, os estudantes ficam menos atrelados ao modelo convencional da aula expositiva. A experimentaçáo pode facilitar o processo de aprendizagem, possibilitar a complexificaçáo do conhecimento, e também elucidar questóes teóricas. Concomitantemente, é necessário implementar açóes que levem os estudantes ao desenvolvimento da teoria, transformando a experimentação em um elemento motivador no ensino de Ciências e Matemática na sala de aula. Seguindo essa linha de pensamento, Borges (1996, p. 58), comenta que "a realização de experimentos, em vez de aulas constituídas somente pela exposição do professor e a leitura de textos, motiva e dinamiza as situaçóes de classe".

\section{b) Experimentação com a função viabilizadora da pesquisa em sala de aula}

Por meio dos depoimentos reunidos nesta categoria, compreende-se que os docentes vislumbram a experimentaçáo como promotora da pesquisa no âmbito da sala de aula, pois possibilita desenvolver a problematização, a elaboração de argumentos e a comunicação.

Acerca da implementação da problematização, os participantes manifestaram que as atividades de experimentação podem ter como função fomentar atitudes questionadoras, o que representa o primeiro passo da pesquisa, como P7 explica: "a experimentaçáa deve estimular os alunos para novas aprendizagens mediante os questionamentos". Para P10, "a experimentação tem como função gerar a problematização, discussão e questionamento, que são elementos básicos para construção do conhecimento".

O questionamento é mola propulsora da pesquisa em sala de aula (MORAES; GALIAZZI; RAMOS, 2012), pois nele está representado o interesse dos estudantes em aprender, que os impulsiona na busca de respostas. Parece relevante que as atividades de experimentaçáo dirijam os estudantes a elaborarem suas próprias perguntas quando possível, evitando-se atividades demonstrativas ou comprovatórias, regidas por roteiros previamente organizados, como destaca P1: "A experimentação deve ser participativa, e não meramente demonstrativa", e também P8: "A experimentação não deve ser entendida apenas como uma ilustração ou demonstração de alguma teoria, mas pode ser o ponto de partida para a busca do conhecimento e do pensamento crítico". A concepção construtivista é defendida claramente nas manifestaçôes destes professores, que apontam a experimentação como uma atividade interativa (MORAES, 2010), sendo ponte para elaboração do conhecimento e desenvolvimento da criticidade.

Pela experimentação, há possibilidade de alcançar novos conceitos. À medida que ocorre o aprofundamento na problematização das ideias, podem emergir 
pensamentos reformulados, a construção de um conhecimento inovador, ou ainda, uma melhor compreensão dos fenômenos estudados. De acordo com P4:

É na interação pedagógica pelo uso de outros instrumentos aliados à prática da experimentação que os fenômenos podem ser compreendidos, como, por exemplo, o diálogo no decorrer do experimento, o questionamento/problematizaçáo, seja no início ou no decorrer da prática que foi realizada, e sua reescrita.

A participação ativa dos estudantes nos procedimentos experimentais instigaos a novos questionamentos, confronta-os com o aprendizado teórico e o surgimento de novas hipóteses no decorrer da prática, propiciando determinada autonomia na tomada de decisóes (HODSON, 1994). Diante da problematização, podem-se desenvolver no educando inúmeras capacidades que promovam o questionamento reconstrutivo (DEMO, 2007), elemento básico para estimular novos aprendizados. A partir do questionamento reconstrutivo, é possível desenvolver a consciência crítica, bem como a formulação e a execuçáo de projetos próprios, capazes de impulsionar a autonomia de quem aprende. Portanto, os estudantes estarão aptos para interferir em sua realidade de forma positiva e ativa, realizando transformaçóes vivenciadas na prática com embasamento teórico.

Sobre o desenvolvimento da elaboração de argumentos, P11 salienta que a experimentação tem como função: "Possibilitar a discussão e a formação de argumentos na interação com o experimento". Na prática, isso pode ser inviabilizado em uma proposta tradicional de ensino. A construçáo de argumentos pela experimentaçáo permite que os estudantes elaborem o seu próprio conhecimento, a partir do momento em que reorganizam seu roteiro de aprendizagem com a reconstrução de conceitos e a interação com seus pares.

O intercâmbio propiciado pelas atividades de experimentação extrapola a manipulaçáo de materiais; no momento em que os estudantes elaboram seus argumentos, capacidades são ampliadas, como a leitura, a escrita e a observação, entre outras que colaboram para a elaboração do conhecimento nas demais áreas. Vale apontar a relevância de promover espaços para que os estudantes possam compartilhar suas ideias acerca das atividades de experimentação (HODSON, 1994).

Para P13, "todas as observaçôes verbalizadas pela turma são válidas, pois são necessárias para a construçáo do conhecimento", podendo servir para que o professor conduza os processos argumentativos, auxilie os estudantes nessa construção e identifique avanços e fragilidades, além de adequar as atividades durante o processo. Com a experimentação, a aula torna-se participativa; é um momento em que questionamentos e argumentos são tratados, quando o professor pode intervir e direcionar os estudantes, conforme relata P3: "Os estudantes devem construir seus experimentos e aprender com os erros e acertos. O professor deve mediar esse processo". $\mathrm{O}$ educando recebe as "ferramentas" para atuar de forma ativa na construção do conhecimento, como esclarece P15: "A experimentaçâo orienta e norteia a capacidade do estudante no aprendizado". 
À medida que constroem argumentos por meio da experimentação, os estudantes podem sentir-se empoderados para formular as suas próprias consideraçóes, como destaca P5: "Através da experimentação, o aluno consegue elaborar suas conclusöes sobre o conteúdo estudado", ou seja, o aluno torna-se participante de seu próprio conhecimento. Isso pode ampliar sua criticidade, a tal ponto de não mais aceitar respostas prontas, passando a construí-las mediante a elaboração pessoal. Em outra manifestação, P5 afirma que: "O experimento serve para que o aluno vire sujeito da construção de seu conhecimento e deixe de ser um objeto". Demo (2007) salienta que a construçáo do conhecimento por meio de atividades que desenvolvam capacidades amplas possibilita deslocar os estudantes da condição de objeto para a de participante do processo de aprendizagem.

O professor P1 compreende que o tipo de experimentação empregada deve privilegiar o envolvimento dos estudantes; ele pondera que a "experimentação deve ser participativa, e não meramente demonstrativa". Para Demo (2007), as aulas focadas em atividades transmissivas, em que os estudantes atuam como espectadores, dificultam a construção do conhecimento. Portanto, compreende-se que as açóes que envolvem experimentação devem privilegiar a participação ativa dos estudantes, sob pena de repetir a lógica da aula expositiva convencional. Para P6, as atividades de experimentação devem investir na discussáo de ideias e em sua exposição: " $O$ professor deve proporcionar momentos de fechamento, em que os estudantes possam apresentar os conhecimentos desenvolvidos na experimentação para a turma. Assim pode ocorrer um confrontamento de ideias que permite validar o que se aprendeu".

À medida que os estudantes passam a ser protagonistas de sua própria aprendizagem a partir da pesquisa (MORAES; GALIAZZI; RAMOS, 2012), desenvolvem capacidades que lhes possibilitam alcançar um nível de aprendizagem expressivo, devido à impregnação dos conceitos formulados e reformulados. Aspectos inerentes ao processo investigativo são valorizados com a intercessão do professor, conforme indica P2: "Nesse sentido, acredito numa via de experimentação investigativa, aliando a essa prática experimental a fala, a leitura e a escrita, num movimento sempre mediado pelo professor".

Na pesquisa, procura-se inovar, descobrir o que está oculto, e a experimentação pode ser uma ferramenta nesta perspectiva. Os estudantes podem ir além do que já conhecem, podem avaliar situaçôes antes não evidenciadas e reconstruir seus conhecimentos sobre um determinado assunto. Demo (2012, p. 57) afirma que "somente o conhecimento que se renova vale a pena e serve para renovar. Guardar conhecimento, estocar, armazenar, apropriar-se dele, adquirir, são expectativas arcaicas que, na prática desfazem a virtude inovadora do conhecimento".

Um dos objetivos da experimentaçáo é desenvolver o conhecimento e tornar os estudantes protagonistas de sua prática. No decorrer do processo, desenvolvemse capacidades, como aprimoramento da escrita, autonomia, operacionalização dos procedimentos experimentais, interpretaçáo de resultados e confrontamento de ideias, entre outras. Acredita-se, então, que a experimentação desempenha papel 
de destaque ao fomentar a pesquisa em sala de aula e privilegiar momentos de questionamento, argumentação e comunicação.

\section{Consideraçóes finais}

O texto teve como objetivo apresentar resposta à pergunta: qual a funçâo da experimentação no ensino de Ciências e Matemática? Por meio da análise do corpus, emergiram duas categorias como respostas a este questionamento: Experimentação com a função facilitadora da aprendizagem e Experimentação com a função viabilizadora da pesquisa em sala de aula.

$\mathrm{Na}$ perspectiva dos participantes deste estudo, a experimentação pode facilitar a aprendizagem ao possibilitar que os estudantes estabeleçam conexóes entre a teoria e a prática, pois os conhecimentos abstratos passam a ser entendidos com clareza e de modo concreto. Tal fato pode ser compreendido a partir do momento em que a experimentação permite elucidar questóes teóricas, conferindo significado ao que se aprende. Os participantes também apontam que a experimentação pode contribuir para o maior engajamento dos estudantes nas atividades escolares, a ponto de se sentirem motivados a aprender. A motivaçáo, entáo, pode ser decorrente do modo prático como os conhecimentos sáo tratados na sala de aula.

Outra função da experimentação, destacada pelos participantes, é que ela pode viabilizar a pesquisa em sala de aula, uma vez que fomenta a interaçáo entre estudante e professor, estabelecendo processos dialógicos. Assim, os argumentos de cada um sáo confrontados dentro de sua realidade. Emergem daí questionamentos, em um processo interacionista entre os participantes e o objeto e vice-versa, em que se problematizam a realidade e as circunstâncias experimentais. É possível operacionalizar a construção de saberes conforme se aprofunda o entendimento sobre o objeto de estudo. Dessa maneira, a experimentação possibilita aos estudantes apresentarem os argumentos construídos, validando-os pela interaçáo com os pares e posteriormente incorporando-os ao seu discurso. Por isso, para P5, "o experimento serve para que o aluno vire sujeito da construção de seu conhecimento e deixe de ser um objeto". Esta mesma perspectiva é defendida por Demo (2007) quando salienta que o protagonismo pode deslocar o estudante da condição de objeto para a de participante do processo.

Cabe reforçar que, entre os professores, há destaque da experimentação como complementação da aula expositiva, de forma que uma não substitua a outra, mas que ambas sejam complementares. Enfatiza-se, ainda, a relevância de as atividades, sempre que possível, serem preparadas para comtemplar açóes investigativas, partindo das inquietudes dos próprios estudantes. Compreende-se que inúmeros fatores podem impedir a realização deste tipo de atividade, como tempo, espaço, materiais e formação, entre outros, porém, em experimentos demonstrativos ou comprovatórios, recomenda-se que o professor estimule o questionamento e promova a discussão. 
Os depoimentos que apontam a função da experimentaçáo podem contribuir para uma reflexão expressiva sobre o tipo de atividade que se propóe em aulas de Ciências e Matemática e sua relação com a concepção de aprendizagem e ensino do próprio professor. Tal reflexão pode auxiliar no planejamento deste tipo de ação, utilizando-se o recurso para a efetiva reconstrução do conhecimento, e não apenas para demonstração ou verificação, o que se aproximaria de uma aula meramente transmissiva.

Para finalizar, recomenda-se ampliar pesquisas relacionadas ao tema, pois a experimentação ainda é vista como uma receita pronta em formato de roteiro, extraída pelo professor de algum recurso disponível, como livros, manuais e internet, entre outros, cabendo ao estudante, muitas vezes, apenas realizar o procedimento previsto, sem que sejam estimulados questionamentos e discussóes.

\section{Referências}

ALMEIDA, M. de A. Seguindo pressupostos da pesquisa na aula expositiva. In: MORAES, R.; LIMA, V. M. R. (Orgs.). Pesquisa em sala de aula: tendências para a educação em novos tempos. 3. ed. Porto Alegre: EDIPUCRS, 2012. p. 175-201.

ALTOÉ, A.; SILVA, H. O desenvolvimento histórico das novas tecnologias e seu emprego na educação. In: __ _ COSTA, M. L. F.; TERUYA, T. K. Educaçáo e novas tecnologias. Maringá: EDUEM, 2005. P. 13-25.

AZEVEDO, A. S.; FARIA, L. Motivação, sucesso e transição para o ensino superior. Psicologia, Lisboa, v. 20, n. 2, p. 69-93. 2006. Disponível em: <http://www.scielo.gpeari. mctes.pt/pdf/psi/v20n2/v20n2a04.pdf>. Acesso em: 18 dez. 2019.

BOGDAN, R.; BIKLEN, Robert. Investigação qualitativa: uma introdução à teoria e aos métodos. Porto: Porto, 2010.

BORGES, R. M. R. Em debate: cientificidade e educação em ciências. Porto Alegre: SE/ CECIRS, 1996.

BRASIL. Secretaria de Educação Fundamental. Parâmetros curriculares nacionais: ensino médio. Brasília: MEC/SEF, 2000.

BRASIL. Ministério da Educação. Secretaria de Educação Básica. Diretoria de Currículos e Educação Integral. Diretrizes curriculares nacionais da educaçáo básica. Brasília: MEC, 2013.

BRASIL. Ministério da Educação. Secretaria da Educação Básica. BNCC - Base Nacional Comum Curricular. Brasília: MEC, 2018. Disponível em: <http://basenacionalcomum. mec.gov.br/images/BNCC_EI_EF_110518_versaofinal_site.pdf $>$. Acesso em: 16 maio 2018.

CACHAPUZ, A.; GIL-PÉREZ, D.; CARVALHO, A. M. P.; PRAIA, J.; VILCHES, A. (Orgs.). A necessária renovaçáo do ensino das ciências. 2. ed. São Paulo: Cortez, 2011. 
DEMO, P. Educar pela pesquisa. Campinas: Autores Associados, 2007.

DEMO, P. Pesquisa como princípio educativo. In: MORAES, R.; LIMA, V. M. R.

(Orgs.). Pesquisa em sala de aula: tendências para a educação em novos tempos. 3. ed.

Porto Alegre: EDIPUCRS, 2012. p. 39-64.

FAGUNDES, S. M. K. Experimentação nas aulas de Ciências: meio para a formação da autonomia? In: GALIAZZI, M. C. et al. (Orgs.) Construçáo curricular em rede na Educaçáo em Ciências: uma proposta de pesquisa em sala de aula. Ijuí: Editora UNIJUÍ, 2007. p. 317-336.

FREIRE, P. A pedagogia do oprimido. 57. ed. Rio de Janeiro: Paz e Terra, 1993.

GALIAZZI, M. C. et al. Objetivos das atividades experimentais no ensino médio: a pesquisa coletiva como modo de formação de professores de ciências. Ciências $\boldsymbol{\&}$ Educaçáo, v. 7, n. 2, p. 249-263. 2001.

GIORDAN, M. O papel da experimentação no ensino de ciências. Química Nova na Escola, n. 10, p. 43-49. 1999.

HODSON, D. Hacia um enfoque más crítico del trabajo de laboratório. Enseñanza de las Ciências, v. 12, n. 13, p. 299-313. 1994.

IZQUIERDO, M.; SANMARTÍ, N.; ESPINET, M. Fundamentación y diseño de las prácticas escolares de ciencias experimentales. Enseñanza de las Ciencias, v. 17, n. 1, p. 45-59. 1999.

LIMA, V. M. R. Pesquisa em sala de aula: um olhar na direção do desenvolvimento da competência social. In: MORAES, R.; LIMA, V. M. R. (Orgs.). Pesquisa em sala de aula: tendências para a educação em novos tempos. 3. ed. Porto Alegre: EDIPUCRS, 2012. p. 203-214.

MORAES, R. O significado do aprender: linguagem e pesquisa na reconstrução de conhecimentos. Conjectura, v. 15, n. 1, jan./abr. 2010. p. 135-150.

MORAES, R. O significado da experimentação numa abordagem construtivista: o caso do ensino de Ciências. In: BORGES, R. R.; MORAES, R. Educaçáo em ciências nas séries iniciais. Porto Alegre: Sagra-Luzatto, 1998. p. 29-45.

MORAES, R.; GALIAZZI, M. C. Análise textual discursiva. 3. ed. Ijuí: Editora UNIJUÍ, 2013.

MORAES, R.; GALIAZZI, M. C.; RAMOS, M. G. Pesquisa em sala de aula: fundamentos e pressupostos. In: MORAES, R.; LIMA, V. M. R. (Orgs.). Pesquisa em sala de aula: tendências para a educação em novos tempos. 3. ed. Porto Alegre: EDIPUCRS, 2012. p. 11-20. 
OLIVEIRA, J. R. S. Contribuições e abordagens das atividades experimentais no ensino de ciências: reunindo elementos para a prática docente. Acta Scientiae, v. 12, n. 1, p. 139-153, jan./jun. 2010.

POZO, J. J. Aprendizes e mestres: a nova cultura da aprendizagem. Porto Alegre: Artmed, 2002.

ROSITO, B. A. O ensino de Ciências e a experimentação. In: MORAES, R. et al. (Orgs.). Construtivismo e ensino de ciências: reflexóes epistemológicas e metodológicas. 2. ed. Porto Alegre: EDIPUCRS, 2003. p. 195-208.

SANTOS, G.; SOUZA, D. N. Experimentação real versus experimentação ideal no ensino de ciências e a prática do pensamento crítico. Scientia Plena, v. 12, n. 11, p. 1-11, 2016.

SOLÉ, I.; COLL, C. Os professores e a concepção construtivista. In. COLL, C. et al. O construtivismo na sala de aula. 6. ed. São Paulo: Ática, 2009. p. 9-28. 